\title{
Investigation of temporal profiles at the symmetrical points of the target in tissue phantoms by time-resolved fluorescence diffuse optical tomography (Withdrawal Notice)
}

\section{Kitsakorn Locharoenrat}

Kitsakorn Locharoenrat, "Investigation of temporal profiles at the symmetrical points of the target in tissue phantoms by time-resolved fluorescence diffuse optical tomography (Withdrawal Notice)," Proc. SPIE 8883, ICPS 2013:

International Conference on Photonics Solutions, 88831I (7 June 2013); doi: 10.1117/12.2014747

SPIE Event: International Conference on Photonics Solutions 2013, 2013, Pattaya City, Thailand 


\title{
Investigation of temporal profiles at the symmetrical points of the target in tissue phantoms by time-resolved fluorescence diffuse optical tomography (withdrawal notice)
}

\author{
Proc. SPIE 8883, 88831I (2013) \\ Online Publication Date: 7 June 2013 \\ Withdrawn from Publication: 8 March 2017 \\ Conference Date: 26-28 May 2013 \\ Conference Location: Pattaya City, Thailand \\ Conference Title: International Conference on Photonics Solutions \\ Conference Chairs: Prathan Buranasiri, Sarun Sumriddetchkajorn \\ K. Locharoenrat \\ King Mongkut's Institute of Technology Ladkrabang, Thailand
}

This paper has been withdrawn by author request. 